\title{
Indigenous Peoples Education: Priorities for Inclusive Education, the Case of Cameroon
}

\author{
Tani Emmanuel Lukong, Ph.D.
}

Educational psychologist, University of Buea,

Fomic Polytechnic University and Founder, Foundation of Scientific Research,

Community Based Rehabilitation and Advocacy on Inclusive Education

(FORCAIE-Buea, Cameroon)

lukongemms_20@yahoo.com

\begin{abstract}
The curricula at various levels must be tuned to lubricate the wheels and make the hub of the Cameroonian education system flexible enough to accelerate the attainment of the new aspirations of Cameroon towards the realization of Vision 2035 which include taking along everybody irrespective of gender, ethnicity, attainment and ability. Indigenous education that recognizes inclusive educational practices is a vital tool for such a holistic long term national goal. At independence, Cameroon introduced an education intervention to ensure that all school going age children had access to education through its education for all policy. This move was adopted taking cognisance of the indispensable role of education in the development of any country. However, the educational set-up in Cameroon has been designed in such a way that indigenous knowledge systems are made to occupy a peripheral position. It is this periferising of the indigenous knowledge systems at a time when Africa, in general and Cameroon in particular, are working towards tailor-making education to become a catalyst for development that is the crux of this paper. The major reflections at the centre of this paper are: Can consideration of indigenous knowledge systems in curriculum innovations be a catalyst in the promotion of inclusive educational practices? Is expanding access to education to all a panacea to linking inclusive education to development and attainment of the millennium development goals in Cameroon? Can educational innovation devoid of the richness of the indigenous knowledge truly result in quality and equitable distribution of opportunities to education for the young generation in Africa in general and Cameroon in particular? These and many other unmentioned questions will be central to the research attempt. An afrocentric perspective is visible both in theoretical and conceptual basis of this paper. Recommendations are made to better enhance inclusive education within indigenous education system.
\end{abstract}

Keywords: Indigenous Peoples Education and Inclusive Education

\section{INTRODUCTION}

There have been diverse opinions on what constitute and reflect indigenous people and indigenous education. The scope has been broadening with the emergence and fusion of inclusive education to achieve and meet educational needs of every student. Marginalized groups, including indigenous peoples, face multiple barriers to education and are being left behind in terms of educational achievement. Developing tailored, culturally and linguistically appropriate educational programmes for indigenous learners should be a priority. It becomes worsen as inclusive educational practices are grossly not available. The most effective way to improve inclusive practices is to work in a community-based, bottom-up manner to ensure that infrastructure, pedagogical materials and curricula meet the sometimes unique needs of indigenous teachers, learners and their communities. Although much work has been done along these lines, with the development of specially tailored school systems and pedagogical approaches, first or identity language instruction and reinforced indigenous knowledge content, these approaches require more support to be properly implemented in all communities of Cameroon where indigenous peoples live. This paper briefly considers the current situation with reference to studies carried out on indigenous peoples' education in recent years, brings to light reflections and mitigation strategies to better enhance inclusive educational practices within or among indigenous people of Cameroon. The paper equally advances a series of recommendations for consideration in the consultation process towards a post-2016 development agenda. 


\title{
1.1. Background
}

Cameroon, like all other African countries has a very rich body of indigenous knowledge systems which find their expression in their technologies, the local education systems, field of medicine, and expertise in animal husbandry, crop production, climatic change control and management. This richness is embodied in the nation's cultural diversities whose humus has nourished the lives of people in the African continent for many centuries. Despite their contributions, indigenous knowledge, skills and technologies are not adequately promoted and protected in most African countries. According to Adam (1991) Indigenous Knowledge Systems (IKS) have attracted the attention of many people resulting in the formulation of policies and legislative frameworks as well as demanding the need safeguard the precious resource has also been a concern of policy-makers across the globe. It is but an undisputed fact that Education is extremely important for indigenous children, youth and adults. As the Expert Mechanism on the Rights of Indigenous Peoples (EMRIP) points out:

\begin{abstract}
"Education of indigenous children contributes to both individual and community development, as well as to participation in society in its broadest sense. Education enables indigenous children to exercise and enjoy economic, social and cultural rights, and strengthens their ability to exercise civil rights in order to influence political policy processes for improved protection of human rights. The implementation of indigenous peoples' right to education is an essential means of achieving individual empowerment and self-determination. Education is also an important means for the enjoyment, maintenance and respect of indigenous cultures, languages, traditions and traditional knowledge...Education is the primary means of ensuring indigenous peoples' individual and collective development; it is a precondition for indigenous peoples' ability to realize their right to self-determination, including their right to pursue their own economic, social and cultural development."
\end{abstract}

During the past 15 years, there have been great gains in both education for instance through the Millennium Development Goals (MDGs) and the Education for All (EFA) movement and indigenous peoples' issues for instance through the adoption of the UN Declaration on the Rights of Indigenous Peoples and the establishment of the UN Permanent Forum on Indigenous Issues, the Special Rapporteur on the rights of indigenous peoples, and the Expert Mechanism on the rights of indigenous peoples. This international instruments which Cameroon is a signatory to, do not only stipulate laws and modalities to enhance indigenous education but develops monitory mechanisms to ensure that quality education of indigenous people is promoted and protected as their undisputed Human Rights. Lukong. T. E (2015)

In deed Significant work remains to ensure that indigenous girls, boys, men, women, communities and societies fully enjoy the right to education, as recognized in a number of international human rights instruments, including the International Labour Organization Convention no. 169 (articles 26 to 31), the Convention on the Rights of the Child (articles 29 and 30), the UN Declaration on the Rights of Indigenous Peoples (articles 12, 13 and 14) and the Universal Declaration of Human Rights (article 26), Education for indigenous peoples as a human right EMRIP (2009); Champagne (2009); and National Model United Nations (2013). Education is a significant initiator of development at the individual, community, national and global levels. For individuals, education is a lifelong asset and one of the most economically sound investments an individual can make.

On average, each additional year of schooling translates into a $10 \%$ increase in an individual's income and every average year of additional schooling translates into a $1 \%$ increase in a country's GDP. This is particularly true for girls a single year of secondary education correlates with as much as a $25 \%$ increase in wages later in life. Education also has broader health and social benefits. Educated women marry later, are less likely to die in child-birth, and have fewer children, more of whom are likely to survive. Individuals who have completed primary school are 50\% more likely to vote in elections, and education has also been shown to dramatically reduce the likelihood of civil war. Education is also at the centre of efforts to address many of today's most critical global challenges including population growth, climate change, urbanization and conflict. National Model United Nations (2013)

It is imperative to emphasize that education for indigenous peoples must be culturally and linguistically appropriate otherwise it may reinforce and perpetuate their marginalization. The UN Committee on Economic Social and Cultural Rights' (UN CESCR) in General Comment No. 13 on 
the Right to Education, reviewing specific legal obligations, asserts that states must: 'fulfill (facilitate) the acceptability of education by taking positive measures to ensure that education is culturally appropriate for minorities and indigenous peoples, and of good quality for all'. The UN CESCR also explains that: 'education has to be flexible so it can adapt to the needs of changing societies and communities and respond to the needs of students within their diverse social and cultural settings'.

\subsection{Reflections}

The major reflections at the centre of this paper are: Can consideration of indigenous knowledge systems in curriculum innovations be a catalyst in the promotion of inclusive educational practices? Is expanding access to education to all a panacea to linking inclusive education to development and attainment of the millennium development goals in Cameroon? Can educational innovation devoid of the richness of the indigenous knowledge truly result in quality and equitable distribution of opportunities to education for the young generation in Africa in general and Cameroon in particular? These and many other unmentioned questions are central to this paper.

\subsection{Statement of the Problem}

Indigenous people in Cameroon view education as an important tool to improve their situation by pursuing economic, social and cultural development; it provides them with individual empowerment and self-determination. Education is also a means for employment; it's a way for socially marginalized people to raise themselves out of poverty. However, Cameroon education systems and curricula lack knowledge about indigenous peoples' ways of learning, causing an Educational Gap for indigenous people. Some schools teach indigenous children to be 'socialized' and to be a national asset to society by assimilating. Thomas-Slater, Kabutha and Ford, (1991) opined that "Schooling has been explicitly and implicitly a site of rejection of indigenous knowledge and language, it has been used as a means of assimilating and integrating indigenous peoples into a 'national' society and identity at the cost of their indigenous identity and social practices'. Intercultural learning is an example of how to build a bridge for the educational gap. The prioritization of inclusive education within indigenous education will greatly fill up the long existing gap educational gap which downplays the local realities of the indigenous people.

African indigenous education is the basis for the foundation of Education for Self-Reliance (ESR) in modern education. During the establishment of ESR in 1967, Nyerere recalled how the traditional education was relevant to the community life-especially learning by doing, and included it in modern education. Learners' participation in learning is highly encouraged by modern educators. Furthermore, it prepared its recipients for life duties in their societies; likewise modern education is no exceptional. It prepares the learners to enter the world of work, and more specifically it changes with time. For example the introduction of information and communication technology course in colleges and universities responds to the current demands of information and communication technology, traditional education also changed in response to societal problems, like how to combat the emerging diseases, wild animals, enemies etc.

African indigenous education has also greatly influenced the need for development of more appropriate problem solving educational curriculum and the promotion of life-long education. Some aspects of African indigenous education have continued to feature in policy and practice of education. Basically African indigenous education managed to provide education to all members of the community, although it differed from tribe to tribe. With the coming of western education however African indigenous education was seen inadequate to contribute to modern world's demands and the need for new skills. The isolationism of African indigenous education was broken up as societies were now introduced into a larger world of modern knowledge and technology. The emergences of inclusive education have demonstrated its relevance in meeting the needs of every learner irrespective of geographic, race, gender and ability. It is therefore this gap which this study aimed at breaching.

\subsection{Theoretical Framework}

It is with imperativeness that this paper adopts an Afro-centric approach to the issue of indigenous people's education and curriculum adaptation for inclusive education. According to Dei (1994) afrocentricity and pedagogy suggest that Afro-centricity becomes intuitively an alternative way of knowing the world, and thus an "...investigation and understanding of phenomena from a perspective grounded in African-centered values...that calls for"... the validation of African experiences and 
histories, as well as a critique of the continued exclusion and marginalization of African knowledge systems, educational texts, mainstream academic knowledge, and scholarship (Dei 1994). This Afrocentric stance is taken against the background of Adams, H. (1991 postulation that no study of the history of education in Africa is complete or meaningful without adequate knowledge of the traditional or indigenous educational system that were prevalent in Africa prior to the introduction of Islam and Christianity. The paper presents a critical appraisal of the utility of the African knowledge systems, the place and role of these local theoretical and philosophical facts within the context of indigenous people's education, and inclusive education practices as well as the possible resurrection of the African epistemology.

Bray, M., et al (2000), contends that discussion on the social construction of knowledge in colonial and post colonial school curricular is of critical importance in any discourses of African educational development. He acknowledges that indigenous knowledge and skills have been relegated to the doldrums of the formal education system and for the establishment of a transformative and inclusive educational system, the indigenous knowledge systems have to be harnessed into the formal education system. Such a move would give voice to the formally marginalized form of education within most African traditional set-ups. For Dziva, D., et al. (2011), knowledge as a historical, cultural, social, spiritual and ideological creation should be a product of collaborated effort from all possible stakeholders to foster development and self-confidents in individuals.

\section{Conceptual Review}

\subsection{Who are Indigenous Peoples?}

Indigenous peoples live on all continents, from the Arctic to the Pacific, via Asia, Africa and the Americas. There is no singularly authoritative definition of indigenous peoples under international law and policy, and the Indigenous Declaration does not set out any definition. In fact, its articles 9 and 33 state that indigenous peoples and individuals have the right to belong to an indigenous community or nation, in accordance with the traditions and customs of the community or nation concerned, and that they have the right to determine their own identity. The International Labour Organization's (ILO) Convention concerning Indigenous and Tribal Peoples in Independent Countries (No. 169) distinguishes between tribal and indigenous peoples as follows, highlighting also the importance of self-identification:

1) Tribal peoples in independent countries whose social, cultural and economic conditions distinguish them from other sections of the national community, and whose status is regulated wholly or partially by their own customs or traditions or by special laws or regulations;

2) Peoples in independent countries who are regarded as indigenous on account of their descent from the populations which inhabited the country, or a geographical region to which the country belongs, at the time of conquest or colonization or the establishment of present State boundaries and who, irrespective of their legal status, retain some or all of their own social, economic, cultural and political institutions.

3) Self-identification as indigenous or tribal shall be regarded as a fundamental criterion for determining the groups to which the provisions of this Convention apply. ... Despite the lack of an authoritative definition, there are criteria that help to define indigenous peoples.

The main one is the criterion of self-identification and those proposed by José Martínez Cobo in his "Study of the problem of discrimination against indigenous populations", which include:

- Historical continuity with pre-invasion and/or pre-colonial societies that developed on their territories;

- Distinctiveness;

- Non-dominance; and

- A determination to preserve, develop and transmit to future generations their ancestral territories and identity as peoples in accordance with their own cultural patterns, social institutions and legal system. The United Nations Permanent Forum on Indigenous Peoples has stressed, in addition to the above:

- A strong link to territories and surrounding natural resources; 
- Distinct social, economic or political systems; and

- Distinct language, culture and beliefs. Many indigenous peoples populated areas before the arrival of others and often retain distinct cultural and political characteristics, including autonomous political and legal structures, as well as a common experience of domination by others, especially non-indigenous groups, and a strong historical and ongoing connection to their lands, territories and resources, including when they practise nomadic lifestyles. While the legal status of indigenous peoples is distinct from that of minorities, they are often, though not always, in the minority in the States in which they reside. Minorities and indigenous peoples have some similar rights under international law, although the United Nations Declaration on the Rights of Indigenous Peoples is arguably more comprehensive than international legal instruments associated with minorities.

\subsection{Concept of Inclusive Education}

The term inclusion has different interpretations in various countries. It is sometimes associated with those students living in marginalized or poor contexts, but frequently it is related to the participation of the disabled or those with special educational needs in mainstream schools. In this way inclusion is considered to be almost the same as integration, when they are in fact two different approaches with different visions and perspectives. As a consequence of this misconception, inclusive policies are regarded as a responsibility of special education, restricting the analysis of all the common forms of exclusion and discrimination that take place within education systems.

UNESCO5 defines inclusive education as a process intended to respond to students' diversity by increasing their participation and reducing exclusion within and from education. It is related to the attendance, participation and achievement of all students, especially those who, due to different reasons, are excluded or at risk of being marginalized. It constitutes an essential element to advance on the EFA agenda. The concept of Education for All does not imply the concept of inclusion. Even though both are intended to ensure access to education, inclusion involves access to high-quality education without discrimination of any kind, whether within or outside the school system. This requires an in-depth transformation of the education systems.

Without inclusion, certain groups of students are likely to be excluded. Inclusion should be a guiding principle for educational policies and programs so that education can be for all and not only for the majority, therefore. Attendance refers to access and continuation in school or other non-formal settings. Participation means that the curriculum and the educational activities address all students' needs, and that students' opinions about decisions affecting their lives and the school are taken into account. Achievements make reference to the need that all students learn, according to their abilities, what is established in the school curriculum and what is required for their personal development and socialization. Real inclusion goes beyond access; it implies learning at the highest level and developing the potential of each individual. Understood in this way, inclusion represents a progress compared with the integration movement.

The aim of inclusion is wider than the aim of integration. The latter seeks to ensure the right of the disabled to study in mainstream schools, whereas inclusion is intended to realize the right of all people to a high quality education, focusing on those who, due to differing reasons, are excluded or at risk of being marginalized. These groups vary depending on the country but, in general, include the disabled, those belonging to an ethnic or linguistic minority, those from isolated or poor areas, children from migrant families or without a birth certificate, those affected by HIV and AIDS, armed conflict or violence. As regards gender, girls are the most excluded in many countries, however in some other countries, the boys are more excluded. Moreover, the focus of inclusion is different from the focus of integration.

In the case of integration, students enrolled in school have to adapt themselves to the existing school environment (curriculum, methods, values and rules), regardless of their mother tongue, culture or abilities. Education systems maintain their "status quo", and actions are more centred on catering for the needs of every particular student (individual programs, differentiated strategies and materials, special education teachers, etc.), rather than modifying those factors of the learning and teaching environment that are barriers to the participation and learning of all. In the case of inclusion, on the contrary, the focus is on the transformation of education systems and schools so that they can cater for 
the diversity of students' learning needs resulting from their social and cultural background and their individual characteristics as regards learning motivations, abilities, styles and rhythm. According to this perspective, it is not the students enrolled in school that must adapt to the existing educational provision, but rather the school that should be adapted to the needs of every student, since all students are different. The key element of inclusion is not individualization but the diversification of the educational provision and the personalization of common learning experiences in order to achieve the highest degree of participation of all students, taking into account their individual needs.

This implies advancing towards universal design, where the teaching learning process and the curriculum consider from the very beginning the diversity of needs of all students, instead of planning on the basis of an "average" student and then carry out individualized actions to respond to the needs of specific students or groups who were not taken into consideration by an education proposal based on a logic of homogeneity instead of diversity. The response to diversity - an essential condition to achieve high quality education - is probably the main challenge currently faced by schools and teachers, as it involves substantive changes in the existing conceptions, attitudes, curricula, pedagogical practices, teacher training, evaluation systems and school organization.

Inclusive education is characterized by the following aspects:

1) It implies a different vision of education based on diversity and not on homogeneity. The old tradition of conceiving differences from normative criteria, what is absent or far from "normality", has led to the creation of options segregated for those categorized as different. According to an inclusive education perspective, the differences are inherent in human nature - each child is unique and unrepeatable - and they are conceived as an opportunity to enrich the learning process, which means that they should be part of education for all rather than the subject of differentiated programs or modalities.

2) The education system as a whole is responsible for responding to diversity which means that it is necessary to shift from homogenous approaches, where all are offered the same, to education models that consider the diversity of needs, abilities and identities so that education can be pertinent for all people and not only for specific groups of society. To achieve pertinence, the educational provision, the curriculum and the teaching-learning process have to be flexible so that they can be adapted to the needs and characteristics of all students and the diverse contexts in which they develop and learn.

3) The curriculum should achieve the difficult balance between responding to commonality and to diversity, offering universal learning opportunities to all students. This should ensure equal opportunities for all but at the same time give sufficient freedom to schools for defining the learning contents necessary to address the requirements of the local context and the educational needs of their students. Relevance also implies developing an intercultural curriculum which promotes the respect for different cultures and the appreciation of differences, and considers in a balanced way the development of different capacities, multiple intelligences and talents of people.

4) It is intended to identify and minimize the barriers encountered by students to access and stay in school, participate and learn. These barriers arise from the interaction between students and different contexts: people, policies, institutions, cultures and socio-economic circumstances affecting their lives. In this respect, actions should be mainly aimed at eliminating the physical, personal and institutional barriers that restrict learning opportunities, as well as at ensuring the full access and participation in all the educational activities for all students.

5) It is a never-ending process as it implies a profound change in the education systems and the school culture. The educational institutions should constantly review their values, organization and educational practices so as to identify and minimize the barriers encountered by students to participate and succeed in learning, seeking more appropriate strategies to respond to diversity and learn from differences.

6) Inclusion also entails support systems which collaborate with teachers in addressing students' diversity, paying special attention to those who need it most in order to optimize their development and improve their learning. This support implies all the resources to complement or reinforce the pedagogical activity of teachers, additional teachers, students who support students, families, specialized teachers, as well as professionals from other sectors. 


\section{Emerging Contextual Conceptualizations on Indigenous Peoples Education AND INCLUSIVE EDUCATION}

\subsection{Efforts in Reaching the Marginalized: Making Education More Inclusive for Indigenous Peoples}

Current trends in education focus on the importance of inclusive practices, characterized by valuing all, respect for differences, and enabling the full participation of all learners including addressing a sense of belonging for all. Progress made in getting children into school was slower than many countries had anticipated during the second half of the 20th century. However, a turning point occurred in the year 2000 with the adoption of the Millennium Declaration and the accompanying MDGs the second of which is to achieve universal primary education by 2015 , and the third of which is to achieve gender parity at all levels of education by 2015. The MDGs galvanized the global community into action and are credited with ensuring an additional 52 million children were in school, 12 as well as making significant strides in reaching gender parity in schools.

Furthermore, according to the Final Evaluation of the Implementation of the International Plan of Action for the United Nations Literacy Decade (UNLD), which ran from 2003 to 2012, the Decade witnessed a growing interest in meeting the learning needs of the marginalized, including indigenous peoples, through inclusive policies and interventions. Unfortunately, in most countries, progress for marginalized groups, including indigenous peoples, has not been as marked as for mainstream groups. Indeed, approximately half of children out of school in the world live in just 12 countries, eight of which are in sub-Saharan Africa. However, even relatively prosperous countries still struggle to get that 'last 5\%' or 'last 10\%' of children into school, while a recent UNESCO study highlights the almost universal attainment gaps between indigenous and non-indigenous primary school students in five Latin American countries. UNESCO's 2010 Education for All Global Monitoring Report, subtitled "Reaching the Marginalized", highlights this issue and concludes that "reaching those who are being left behind as a result of disparities linked to poverty, gender, ethnicity, language and other markers of disadvantage should be established as a first order of priority."

In part, this is because barriers to education that impact differentially upon indigenous peoples have not been adequately tackled. Children from poor communities, ethnic minority groups and indigenous peoples face three main barriers. The first of these is lack of access. For children to receive an education there must be a school within safe travelling distance, with teachers and pedagogical materials. In Cameroon, this is often not the case, especially for ethnic minorities and indigenous peoples who tend to live in remote areas or Fulani herdsmen who move around.

The second barrier is the poor quality of the education provided. In Cameroon Children from the poorest communities often have inferior educational institutions than those from richer communities. Children from ethnic minorities may be denied the opportunity to learn in their own language and their curricula and educational materials may be grounded in an alien culture. They may even be faced with social stigmatization. The third barrier is relatively poor outcomes. Children from ethnic minorities and indigenous peoples do not enjoy the same benefits from education as other children. They find it harder to get jobs, and their education often does not lead to significant contributions to life in their community. All these are visible among the Nso people as highlighted by Lukong. T. E (2014)

The Deprivation and Marginalization in Education (DME) dataset has also highlighted the fact that multiple risk factors of deprivation are additive: "Gender, poverty, language and culture often combine to radically heighten the risk of being left far behind." A number of studies have shown that indigenous girls may be less likely to participate in and benefit from education than indigenous boys or non-indigenous girls, while poor indigenous girls are at the most risk of all. For instance, in Nigeria, $97 \%$ of poor Hausa-speaking girls have fewer than two years of education. In Paraguay, only $16.8 \%$ of indigenous girls aged 15-19 had completed primary school in 2002, compared to $25.6 \%$ of indigenous boys and $83.7 \%$ of non-indigenous girls. Many of the studies on educational attainment focus on basic, primary and secondary education. UNESCO's 2010 EFA Global Monitoring Report also emphasized the importance of ensuring second chance and vocational education for increasing the inclusivity of education systems for marginalized adults. A number of studies have shown that indigenous peoples often register lower levels of adult literacy rates than the majority groups. Improving adult's literacy skills have many positive economic, social 
and even health impacts, and may even improve their children's education. While some countries have made impressive efforts to tackle these barriers and extend educational opportunities to the most marginalized, action has fallen short of EFA goals and much work is still to be done.

\subsection{Conceptualizing Indigenous Peoples and Education: Increased Awareness at the Global Level}

For the past 20 years, indigenous peoples have gained more visibility and their situation has been better addressed by UN agencies, most demonstrably through the adoption in 2007 of the UN Declaration on the Rights of Indigenous Peoples and the issuance in 2008 of the UNDG Guidelines on Indigenous Peoples' Issues, which identifies education as one of eight key issues that UNCTs should address when programming. UNESCO and UNICEF are working to improve education for indigenous peoples through a range of projects and initiatives. For instance, UNESCO published the book The Challenge of Indigenous Education: Practice and Perspectives", which identifies the emerging opportunities for quality indigenous education through an evolving intergovernmental policy framework.

It notes that in all too many situations implementation lags behind what was hoped for when the policies were put in place; and highlights examples of good practice that can be used for putting in place such programmes. As the case studies in the volume make clear, the challenge of developing education programmes for indigenous peoples is multifaceted and complex. Nevertheless, insufficient progress has made towards the realization of the recommendations made in 2004. One key lesson to be learned is that each indigenous people and each region must develop unique programmes that reflect their unique languages, world views, cultures, livelihoods and histories. This is a wake-up call for Cameroon as an active partner of the UN to effectively and adequately ensure that such programmes are developed to mitigate the educational challenges faced by indigenous people peoples in Cameroon.

\subsection{Culturally Appropriate Education for Indigenous Peoples: Cameroon as a Thriving Example of Good Practice}

The Convention on the Rights of the Child (CRC) recognizes the primary importance of culture. Under the CRC, states (countries including Cameroon) have an obligation to preserve and protect the child's cultural identity, as an essential element for his or her development. The Preamble recognizes the 'importance of the traditions and cultural values of each people for the protection and harmonious development of the child'. Articles 8, 20 and 30 all touch on the right of children to their cultural, ethnic, religious and linguistic identity. While, it is thus well-acknowledged within the international framework that culture is a key element for the development of the child, the translation of these norms into culturally appropriate education systems remains a challenge for many countries.

It may be helpful, therefore, to highlight several examples of good practice. Active and multicultural pedagogical methodologies offer tools for improving access to quality education for indigenous peoples. The "Observer, réfléchir, agir" (Observe, think, act) (ORA) teaching method is a bilingual and intercultural education method originally developed by educators working with the Baka people of Cameroon. Sometimes called the "mommy method" because it follows a similar method used by the Baka when they learn in the forest and because it is used in the mother language, the method has been adapted to other cultural contexts in Central Africa, particularly as a means of improving learning outcomes for early childhood education and supporting indigenous children to acquire the basic skills they will require to be successful in primary education. In some cases, for instance in the Pacific or the Arctic, the use of Open Educational Resources can help to overcome geographical and infrastructural barriers to provide appropriate educational materials to indigenous peoples thereby enhancing inclusion among local communities.

Not with standing, bilingual and intercultural education method although both languages are equally included in the curriculum, the modality and the weight of each language use may vary. Typically, the literacy process starts in the child's mother tongue, while the second language is gradually introduced, so that writing skills are learned just once. Later the child transfers what she or he has already learned to the other language. Education should also take into consideration the content, values and knowledge of indigenous cultures as well as those of the rest of society. In this way, indigenous languages and cultures become important pedagogical resources. 
In recent years, there has been a paradigm shift regarding intercultural education. Initially, it was often associated with bilingual education for indigenous children. But it is now considered a modality for the entire educational system, not only for indigenous groups. "Intercultural Education for ALL" (IBE) has been the new trend for educational debates and legal reforms for this sector which Cameroon is gradually adopting. Evidence suggests that IBE has been successful. Learning achievement evaluations show that children participating in IBE classes perform better than control groups, both in their first and second languages. For adolescents, cultural awareness proves to be a strong element for improving self-esteem. Through IBE programs, communities have been more involved in education activities, often in the planning and management of school action plans. The use of indigenous languages and the inclusion of indigenous knowledge in the curriculum have increased the interest of both families and students in their history, and in their present and future learning and development opportunities.

However, IBE programs are not without their flaws. Common problems include: unsatisfactory attainment in global curricula and national languages; additional challenges for poorly supported teachers in rural settings; lack of sustained and secure funding; difficulty recruiting appropriately qualified teachers; and lack of infrastructure. However, if these issues are overcome, IBE can be truly transformative for indigenous peoples, reinforcing their identity, language and traditional knowledge, while at the same time offering expanded options for success throughout life, thereby repaying any additional investment that may be required.

\section{Conclusions ANd ReCommendations}

The start point of our argument is that significant contributions to global knowledge have originated from indigenous people, the rational nature and sophistication of rural people's knowledge and believe that knowledge can be blended with or incorporated into formal scientific knowledge systems. If local knowledge and capacities are granted legitimacy within the scientific and development communities, existing research and extension services will pay greater attention to the priorities, needs, and capacities of rural people and, in the end, achieve more effective and lasting results. The promotion of indigenous methods of education and the inclusion of traditional knowledge also enables those in Western and post-colonial societies to re-evaluate the inherent hierarchy of knowledge systems. Indigenous knowledge systems were historically denigrated by Western educators; however, there is a current shift towards recognizing the value of these traditions. The inclusion of aspects of indigenous education requires the acknowledgement of the existence of multiple forms of knowledge rather than one, standard, benchmark system. Many scholars in the field assert that indigenous education and knowledge has a 'transformative power' for indigenous communities that can be used to foster 'empowerment and justice'. The shift to recognizing indigenous models of education as legitimate forms is therefore important in the ongoing effort for indigenous rights, on a global scale. Over the past decade or so, important lessons have been learnt about improving outcomes for indigenous peoples in the educational sphere. This paper however recommends that:

* Mother language instruction is recommended for indigenous children, youth and adults. Children learn best in their mother tongue. However evident this may appear, there are still many countries where, by law, all education must take place in the national language. Children who don't speak that language are at a significant disadvantage from their very first day in school.

* Many Cameroonian indigenous languages are endangered or on the verge of extinction. Where the indigenous language is not the mother language (i.e. where the identity or heritage language is not being transmitted from generation to generation), language revitalization programmes should be integrated into the education system.

* Formal education should not only teach about the outside world, but should also support and value traditional knowledge, culture, livelihoods, world views and pedagogical methods that meets inclusive educational objectives. To do this appropriately inclusive infrastructure, curricula and pedagogical materials should be tailored to the unique needs of every indigenous learners, communities and peoples. This may include modified schedules, distance learning initiatives, mobile schools and culturally and linguistically appropriate pedagogical materials. 
* Indigenous peoples should identify their own educational priorities and curriculum and pedagogical material development, inclusive teacher training and education delivery should be planned and implemented with the active involvement of the indigenous community.

* An emphasis should be placed on capacity-building for teachers, including that they are able to teach in the mother- or ethnic- language of the students, that they are prepared for and understand the importance of involving the community in formal education and that they understand and work to the strengths of their learners. This includes ensuring professional-scale remuneration on par with teachers in non-indigenous communities.

* National curricula and materials should also be intercultural, and should include accurate information about indigenous peoples, their cultures, their histories and lived experience. Negative and discriminatory stereotypes should be removed from the curricula and materials of all schools and educational institutes, not just those of indigenous learners.

* To enable full understanding of the education gap and the barriers to education faced by indigenous learners, accurate monitoring and disaggregated data is required.

In the push for Education for All, improving access, quality and outcomes for marginalized populations, including indigenous peoples, must not be overlooked. To not leave out indigenous learners, education must be tailored to their needs, including their geographical, infrastructural, livelihood, cultural, historical and linguistic contexts. It is also necessary to highlight that educational marginalization for indigenous peoples occur within a context of disproportionately high poverty and hunger, decreased security, and loss of identity, language, territories and livelihoods. An attention to all the rights of indigenous peoples and support for sustainable economic, cultural and social development is fundamental to improving their inclusive educational outcomes.

\section{REFERENCES}

[1] Adams, H. (1991). "African Observers of the Universe: The Sirius Question" in Blacks in Silence: Ancient and Modern, ed. Ivan Van Sertima. New Brunswick, NJ: Transaction Books.

[2] Bray, M., Peter C. and D. Stephens (2000). "Indigenous Forms of Education: The Individual and Society" in Brock-Unte, Birgit. Whose Education for All: Recolonization of the African Mind. New York: Falmer Press.

[3] Champagne, D. (2009), Contemporary Education in State of the World's Indigenous Peoples, Ch. IV. UN Department of Economic and Social Affairs, ST/ESA/328.

[4] Dei, G. (1994) "Afrocentricity: A Cornerstone of Pedagogy" in Anthropology \& Education Quarterly.

[5] Dziva, D., Mpofu, V. and Kusure, L.P. (2011) "Teachers' concept of indigenous knowledge in science in the context of Mberengwa District, Zimbabwe". African Journal of Education and Technology Vol (1) No 3

[6] EMRIP (2009), Study on lessons learned and challenges to achieve the implementation of the right of indigenous peoples to education: Report of the Expert Mechanism on the Rights of Indigenous Peoples.

[7] Gakidou, E., K. Cowling, R. Lozarno and C.J.L. Murray (2010) Increased educational attainment and its impact on child mortality in 175 countries between 1970 and 2009: a systematic analysis, Lancet, 376 (9745): 959-74

[8] Hanusek, H.A. and L. Woessman (2010) The Economics of International Differences in Educational Achievement. National Bureau of Economic Research, Working Paper 15949.

[9] King, L. and S. Schielmann (2004) The Challenge of Indigenous Education: Practice and perspectives. Paris: UNESCO.

[10] Klassen, S (1999) Does Gender Inequality Reduce Growth and Development? Policy Research Report on Gender and Development Working Paper No 8, World Bank.

[11] López, L.E. and U. Hanemann (eds.) (2009) Alfabetización y Multiculturalidad: Miradas desde América Latina. Guatemala: UNESCO Institute for Lifelong Learning and Programa de Apoyo a la Calidad Educativa de la Cooperación Técnica en Guatemala (PACE-GTZ) 
[12] Lukong. T. E (2015) Integrating Indigenous Knowledge in Cameroon's Formal Education System: It's Potential for Contextual Quality Education, African Journal of Social Sciences Volume 6, Number 1.

[13] Manga Ndjie Bindzi Mballa, H. (2009) Les Pygmées Face à l'Ecole et à l'Etat: Les Baka de l'estdu Cameroun. L'Harmattan.

[14] Mathur, S., M. Greene and A. Malhotra (2003) Too Young to Wed: The lives, rights and health of young married girls. Washington, DC: International Center for Research on Women.

[15] Messe, Venant (2008) Le cas de l'éducation des enfants baka de la commune rurale de Mbang au Cameroun. Recherche sur les bonnes pratiques pour la mise en oeuvre des principes de la Convention 169 de l'OIT. Etude de cas 2. ILO.

[16] Mosselson, J., W. Wheaton and P. S. Frisoli (2009) Education and Fragility: A Synthesis of the Literature. Journal of Education for International Development.

[17] National Model United Nations (2013) Improving Access to Education in United Nations Permanent Forum on Indigenous Issues: Background Guide, part I.

[18] Nyerere J.K (1979) Education for Self Reliance, In Hinzen, H. and Hundsdorfer, V.H. (eds.) Education for Liberation and Development: The Tanzania Experience, Tanzania: Hamburg and Evans.

[19] Psacharopoulos, G. and H.A. Patrinos (2002) Returns to Investment in Education: A Further Update, World Bank Policy Research Working Series 2882 Trevion, E., E. Villalobos, F. Godoy and F. Donoso (in prep).

[20] Thomas-Slater, B., Kabutha, C. and Ford, R. (1991). Traditional Village Institutions in Environmental Management. From the Ground up Case Study Series, Washington, DC: The Center for International Development and Environment, World Resources Institute, and Nairobi: the African Centre for Technology Studies.

[21] UN Committee on Economic, Social and Cultural Rights (UN CESCR) (1999) General Comment No. 13: the Right to Education (Art. 13 of the Covenant).

[22] UNESCO (2008) Education for All Global Monitoring Report: Education for All by 2015-Will we make it?

[23] UNESCO (2010a) Education for All Global Monitoring Report: Reaching the Marginalized. Paris: UNESCO.

[24] UNESCO (2010b) Education for All Global Monitoring Report: Reaching the MarginalizedSummary. Paris: UNESCO.

[25] UNESCO (2011) Education for All Global Monitoring Report: The hidden crisis: armed conflict and education. Paris: UNESCO.

[26] UNESCO. (2012) Education for All Global Monitoring Report: Youth and skills: Putting education to work. Paris: UNESCO.

\section{AUTHOR's BIOGRAPHY}

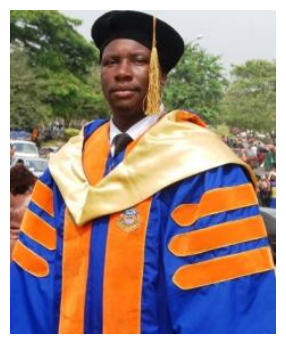

Dr. Tani Emmanuel Lukong is an Assistant Professor of Inclusive Education and Educational Psychology. Tani Emmanuel has a PhD in Psychology of Education with Triple Concentration in, Inclusive Education, Cognitive and Developmental Psychology and Applied cultural Psychology, a Master Degree in Psychology of Education and Bachelor's degree in Special Needs Education. Dr. Tani Emmanuel is a University lecturer and the founder of "Foundation of Scientific Research, Community Based Rehabilitation and Advocacy on Inclusive Education" (Forcaie-Cameroon). A Research Organization aimed at building mutual-help, Equal Participation, Accessible Society with Love and care through the Utilization of Available Resources in Building up an Inclusive Rehabilitation Platform which promotes the Equal Participation of people with disabilities and enhances Community Development. Dr. Tani is a Research Consultant and Inclusive Education Specialist. 